$5-2018$

\title{
The Marginalization and Stereotyping of Asians in American Film
}

Isabel Paner

Dominican University of California

https://doi.org/10.33015/dominican.edu/2018.HONORS.ST.08

Survey: Let us know how this paper benefits you.

\section{Recommended Citation}

Paner, Isabel, "The Marginalization and Stereotyping of Asians in American Film" (2018). Honors Theses. 36.

https://doi.org/10.33015/dominican.edu/2018.HONORS.ST.08

This Honors Thesis is brought to you for free and open access by the Student Scholarship at Dominican Scholar. It has been accepted for inclusion in Honors Theses by an authorized administrator of Dominican Scholar. For more information, please contact michael.pujals@dominican.edu. 


\title{
The Marginalization and Stereotyping of Asians in American
}

\section{Film}

\begin{abstract}
Asians in Hollywood films and the industry have been subjected to unfair stereotyping and under-representation since the twentieth century and up to the present. This thesis analyzes and dissects this marginalization and stereotyping of Asians in American films through text and film analysis and critical theory. Historically, if Asians are not portrayed in a stereotypical role, then they are given no role at all, rendered invisible by Hollywood and mass audiences. Their marginalization in the film industry has damaging effects on the perception of Asians in society. This study will explain what stereotypes have endured over the course of history, their origin and reasoning, and how films continue to portray them. Research will not only cover Asian stereotypes as a whole, but also gender stereotypes attributed to Asian men and women because of their race. This study will also dissect the societal consequences that arise from detrimental portrayals of Asians in Hollywood, including the negative impact of the "model minority" stereotype often attributed to AsianAmericans and the effects on Asians in the entertainment industry. By relating portrayals of Asian stereotypes in film to societal effects, this study emphasizes how fictitious portrayals can have damaging effects once taken outside the realm of film.
\end{abstract}

Document Type

Honors Thesis

Degree Name

Bachelor of Arts

Department

Communication and Media Studies

First Reader

John Duvall, PhD

Second Reader

Amy Wong, PhD

\section{Keywords}

Asian-American, stereotype, Hollywood, film, marginalization, representation, DEI

\section{Subject Categories}

Broadcast and Video Studies | Communication | Gender, Race, Sexuality, and Ethnicity in Communication 


\title{
The Marginalization and Stereotyping of Asians in American Film
}

\author{
By \\ Isabel Paner \\ Submitted in partial fulfillment of the requirements of the Department of Communication \\ and Media Studies and the Honors Program \\ Dominican University of California \\ 2018
}

First Reader: $\underline{\text { John Duvall }}$

Second Reader: Amy Wong

Honors Director: Dr. Gigi Gokcek Department of Political Science/International Studies
Department of Communication and Media Studies

Department of English 
This thesis, written under the direction of the candidate's thesis advisor and approved by the Chair of the undergraduate program, has been presented to and accepted by the Faculty of the Department of Communication and Media Studies in partial fulfillment of the requirements for the degree of Bachelor of Arts. The content and research methodologies presented in this work represent the work of the candidate alone. 


\begin{abstract}
Asians in Hollywood films and the industry have been subjected to unfair stereotyping and under-representation since the twentieth century and up to the present. This thesis analyzes and dissects this marginalization and stereotyping of Asians in American films through text and film analysis and critical theory. Historically, if Asians are not portrayed in a stereotypical role, then they are given no role at all, rendered invisible by Hollywood and mass audiences. Their marginalization in the film industry has damaging effects on the perception of Asians in society. This study will explain what stereotypes have endured over the course of history, their origin and reasoning, and how films continue to portray them. Research will not only cover Asian stereotypes as a whole, but also gender stereotypes attributed to Asian men and women because of their race. This study will also dissect the societal consequences that arise from detrimental portrayals of Asians in Hollywood, including the negative impact of the "model minority" stereotype often attributed to Asian-Americans and the effects on Asians in the entertainment industry. By relating portrayals of Asian stereotypes in film to societal effects, this study emphasizes how fictitious portrayals can have damaging effects once taken outside the realm of film.
\end{abstract}

Keywords: Asian-American, stereotype, Hollywood, film, entertainment, marginalization, representation 


\section{Table of Contents}

Introduction - p. 5

Positionality - p. 6

Methodology - p. 7

Research Questions - p. 9

Literature Review — p. 9

I. The History Behind Asian-American Marginalization in Film — p. 9

II. Stereotyping of Asian Women in Hollywood Film - p. 12

III. Stereotyping of Asian Men in Hollywood Film - p. 16

IV. The Effects of Stereotyping and Marginalization on the Industry — p. 19

V. Effects of Stereotyping and Marginalization on Asian-Americans - p. 23

Conclusion - p. 27

References - p. 29 


\section{Introduction}

According to the 2010 U.S. Census Bureau, over 17 million people identify as Asian or Asian-American, but this growing population is not reflected in Hollywood. Asian-Americans are almost as invisible in Hollywood as they were fifty years ago, as studies show only 5.3 percent of roles in 2014 films were Asian (Smith et al., 2015). As Rajgopal (2010) points out in her study of Asian women in film, when Asians are given roles in Hollywood, they are often stereotyped; men are stripped of their masculinity and women are unfairly painted as either a "dragon lady" or a "china doll." Asians are also stereotyped as "nerds," donning glasses and an exaggerated accent, or as Kung Fu masters and killers (Rajgopal, 2010). Indeed, the infamous "model minority" stereotype that portrays Asians as intelligent, hardworking, and ambitious, does more harm than good. It boxes Asians into an "othered" role, deeming them as passive foreigners without dimension. These stereotypes do not just stay on screen, but instead bleed into how Asians are perceived outside of media, leaving detrimental cultural and social consequences and leading to feelings of inferiority.

In addition, the erasure of Asian-Americans in Hollywood perpetuates the idea that Asians are still foreigners, unworthy of well-rounded representation and storytelling. Historically, some films have actors don yellowface, such as Breakfast at Tiffany's (1961), where Mickey Rooney plays a bucktoothed, slant-eyed Mr. Yunioshi (Rajgopal, 2010). This practice has remained in more recents films For instance, instead of casting Asian actors, Cloud Atlas (2012) featured Jim Sturgess and Keith David in yellowface; their makeup is meant to make them appear ethnically Korean to fit the futuristic Korea 
in which part of the movie was set (Rose, 2016). Other films completely whitewash roles intended for Asian characters, such as Ghost in the Shell (2017), adapted from the Japanese manga of the same name, and Aloha (2015), which has Emma Stone portraying Allison Ng, a fighter pilot of partially Vietnamese descent. In Ghost in the Shell, Scarlett Johansson, a white actress, is cast as Motoko Kusanagi, the Japanese protagonist. Additionally, in Marvel's Doctor Strange (2016), Tilda Swinton plays the Ancient One, who is originally a Tibetan monk changed to a white woman for the film (Rose, 2016).

Hollywood also has a habit of indiscriminately casting any Asian actor in any Asian role; a Chinese actor may portray a Korean character, and vice versa. This perpetuates the idea that Asia is a monolith with interchangeable cultures even though Asia is made up of dozens of countries, each with their own different culture and traditions. These instances not only maintain the invisibility of Asians in the media, but take away jobs from Asian actors who rightfully should be playing these roles. Thus, this paper aims to dissect the marginalization and stereotyping of Asian-Americans in the Hollywood film industry, including how history shaped the perception of Asian-Americans as foreign and "un-American."

\section{Positionality Statement}

As a cisgender, Asian-American female conducting research on the marginalization and stereotyping of Asians in Hollywood film, my identity puts me in a position that relates to other Asian-American women and how they are affected by the media. I can also relate to other Asian-American men because we are the same race, but I 
cannot relate when it comes to gender issues. I am also Filipino and Chinese, meaning that I will relate more to people of these ethnicities, and I can relate to experiences a mixed-race individual can have. However, I will not have the same experiences as a Thai or Indian individual, though there are diasporic experiences that we may have in common as Asians living in the United States. Intersectionality also plays a large role in dissecting cultural nuances and their effects on society. I also am able to pursue my interest in cinema and the entertainment through this thesis by dissecting its nuances and societal effects. It is important to me to convey that fiction does not exist solely in the sphere of entertainment.

\section{Methodology}

The methods I have used to conduct my study are text analysis and critical theory; by analyzing different text and visual content, I can properly answer my research questions pertaining to the marginalization and stereotyping of Asian-Americans in Hollywood. The articles I have chosen for my research encompass a variety of topics under the umbrella of marginalization and stereotyping of Asian-Americans, including stereotyping of Asian men and women, yellowface, the Western gaze and how the West views the East, and how Asian women are dressed in film. I have also decided to analyze articles that cover the effects of stereotypes in society, such as how people view Asians when exposed to stereotypes. For example, by analyzing Yuko Kawai's (2015) study on the "model minority" stereotype, I can further understand how stereotyping Asians as 
intelligent and ambitious yet foreign, antisocial, and awkward can be detrimental to interactions with and the perception of Asians in American society.

One of the most important methods underneath text analysis is critical analysis, which I will use to explore how Hollywood portrays Asians in film, how people respond to prejudice in Hollywood (such as average Asian-Americans, Asian-Americans in the industry, bloggers, and scholars), and how portrayal in media has an effect on society instead of just simply existing in a fictional sphere. Using critical analysis, I can analyze interviews done with Asian-Americans in the industry, such as actors, directors, and producers, and how they feel about Hollywood and its treatment of Asians. Although scholarly articles are essential to my research, it is important to analyze online sources aligning with more current issues, such as scholarly publications and journals found online or popular media outlets reporting on media. For example, I have turned to sources such as Vanity Fair and the National Organization for Women. I also analyzed the portrayal, stereotyping, and representation or misrepresentation of Asians in Hollywood films.

In addition, I have looked at whether or not Asian actors have been cast for a role, and if not, if a white actor was cast instead. It is important to include films from the beginning of the film industry to the present in order to see how history directly correlates with the portrayals of Asian-Americans in film; how portrayals and representation have shifted as time has passed; how stereotypes began; and why some aspects (yellowface, whitewashing, stereotyping, and the underrepresentation of Asian-Americans in Hollywood) still continue to persist in spite of protest against 
prejudice. I have also included more current films, such as Doctor Strange (2016) and Cloud Atlas (2012). Instead of taking these films at face value, I am going to analyze both the implicit and overt elements that contribute to offensive and stereotypical roles of Asian-Americans. By analyzing over a dozen films spanning from the era of silent film to now, I am able to trace the transformation (or lack thereof) of Asian representation in Hollywood over time and how that has affected American society. Furthermore, this paper will go into how audiences consume stereotypes, which do not just exist in a fictional sphere. Stereotypes, which can be played for laughs, are ultimately harmful by normalizing a singular role about a group. Despite this concern, stereotypes are still perpetuated in current films when diversity in Hollywood is supposed to be improving instead of taking steps backward. Through both my own analysis and the analyses of other sources, I am able to draw evidence to support my argument through these films.

\section{Research Questions}

This thesis aims to answer the following questions:

1. What stereotypes are often attributed to Asians and how is this stereotyping in media detrimental to the way Asians are perceived in American society?

2. Why is stereotyping seen as a joke when stereotypes can cause harm?

3. Why are there limited roles of Asians, of which many are typecast, and how does this affect Asians in the industry? 
4. What is the history behind the underrepresentation of Asians in film and how have they been "othered" by the film industry?

\section{Literature Review}

The History Behind Asian-American Marginalization in Film

Because the West was not hugely exposed to the East, "the easiest way to generalize Eastern people was to build fictional characters of an extreme" (Wang, 2010, p. 86). Asians were not talked about, and when they were, it was through caricatures and suppression. Following the Chinese Exclusion Act in 1882, which suspended Chinese immigration for ten years and did not allow naturalization for the Chinese already living in the United States, and the rise of "Yellow Peril" in America, when "the Chinese exemplified the menace of the Asian other" (Rajgopal, 2010, p. 147), Asians were portrayed unfavorably in media. The genius, manic villain whose goal was to destroy the West, Fu Manchu, was a particularly notorious example. Created by British author Sax Rohmer, he was brought to life in American films as a reaction to the appearance of Chinese immigrants during the Gold Rush. Like other Asian roles of the early twentieth century and sometimes even in current cinematic films, Fu Manchu was played by several white actors, including Harry Agar Lyons and Warner Oland. Other villainous portrayals include the villain Ming from the Flash Gordon films in the 1950s and Anna May Wong's role in Shanghai Express (1932) as a "wicked Asian vamp" (Rajgopal, 2010, p. 148). The portrayal of Asian-Americans in Hollywood correlated with the perception of Asians at the time, with negative stereotypes coinciding with the time 
period. Tracing the history of Asian-Americans, illustrates how history shapes the course of Hollywood film and its treatment of Asians.

To emphasize the effect of history in Asian representation in media, the Japanese were the ones portrayed in a starkly negative light during World War II despite the Chinese being America's former favorite for the "evil Asian." Instead, during this time, the media deemed them docile, passive peasants (Mok, 1998). Following the Communist takeover of China in 1949, the Chinese were once again back in the negative light in American media. If Asians were not played as villainous, then they were played for laughs, such as a yellowfaced Mickey Rooney in Breakfast at Tiffany's. Furthermore, the role of a "good Asian" was meant to serve the white man, often betraying their own people to do so. An example would be Gunga Din, the Indian servant in Gunga Din (1938), who saves British sergeants at the expense of his own life and thus betraying his people (Rajgopal, 2010).

Asian women were particularly treated unfairly following the 1960 s and 1970 s as spoils of war, portrayed as prostitutes and peasants needing to be rescued by the white man (Mok, 1998). This portrayal fed into the stereotype that Asian women were spineless, submissive dolls ready to dote on white men. In addition, Western beauty standards are projected onto Asian women, as well, especially onto South Asian women. Portrayals in media emphasize a lighter skin is more beautiful than a dark one, which can be damaging to the self-esteem (Thakore, 2014).

Anna May Wong, one of the most prominent actresses of the early twentieth century, was limited when it came to roles despite her fame. As an actress of color, she 
was subject to anti-miscegenation laws enforcing racial segregation in intimate relationships and marriage even onscreen, and could not be the leading lady to a leading white man (Rajgopal, 2010). This meant despite her success and extensive filmography, she could only be cast in secondary roles. Many of these roles were rooted in stereotypes as a villainous, seductive "dragon lady" or the forlorn love interest cast aside when the leading man found a happy ending with a white woman. To illustrate this typecasting, in The Toll of the Sea (1922), Wong played the role of Lotus Flower, a Chinese village girl who rescued American Allen Carver, played by Kenneth Harlan. The two fell in love and had a son, but Carver ultimately had to return to America, leaving behind a pining Lotus Flower struck by tragedy but clinging to the hope he would return. When he did, he came back with an American wife. Hence, Lotus Flower gave her son to the couple to raise and threw herself in the sea out of despair and resignation that she would not be Carver's wife (Hodges, 2012).

When criticized for perpetuating stereotypes with her roles as doomed lovers and temptresses, Wong refuted that she had little choice if she wanted to find roles, and she also wished American film would expand Asian roles beyond harmful stereotypes (Wang, 2012). Moreover, despite no shortage of Asian-American actors looking for a role, Asian roles would go to white actors. The Chinese peasant woman O-lan in The Good Earth (1937) a film adaptation of Pearl S. Buck's novel, was played by white actress Luise Rainer in yellowface with her eyes taped back instead of Anna May Wong. (Rajgopal, 2010). Perhaps adding insult to injury, Rainer won an Academy Award for Best Actress for her role in The Good Earth. 
Stereotyping of Asian Women in Hollywood Film

Although anti-miscegenation laws were eventually removed and Asian actresses could star opposite white men if given the chance, they were still boxed into stereotypical roles of two extremes. Movies produced in the late twentieth century still suffered from stereotypes set by films from years ago. In Year of the Dragon (1985), Tracy Tzu, despite being a professional newscaster, is portrayed as seductive and mysterious, "manhandled and dominated by the Caucasian hero, Stanley White, as he overpowers her and carries her off to bed like a trophy" (Rajgopal, 2010, p. 149). Suzie Wong of The World of Suzie Wong (1960) is an orphaned, illiterate prostitute who captures the heart of Robert Lomax, an American man who had escaped to Hong Kong. The film is based on a novel of the same name, and ends with Robert rescuing Suzie from Hong Kong's red light district. By becoming her white knight and marrying "his China Doll, he could escape the confines of his own world and find the exotic realm of the Oriental" (Wang, 2013, p. 77).

Even more nuanced and more current performances fall victim to the opposing stereotypes of a "dragon lady" and a "china doll" (also known as a "lotus blossom"). Zhang Ziyi plays Hu Li in Rush Hour 2 (2001), a henchwoman and another "dragon lady." Her character is dangerous, seductive, and ruthless, while other Asian women in the film are depicted in massage parlors, portrayed as submissive and weak (Park, Gabbadon, \& Chernin, 2006). In The Wolverine (2013), Tao Okamoto plays Mariko, who “tempted Wolverine from his past true love, Jean Grey, and required his protection the entire film" (Chong, 2016). In Tomorrow Never Dies (1997), Michelle Yeoh portrays a 
Bond Girl and a Chinese secret agent. Despite having brains, martial arts prowess, and beauty, she is still trapped in a "dragon lady" role as she is also steely and controlled, representing the East as opposite to the West (Wang, 2010).

Asian women are victims of Orientalism, or the othering of Asia and the Middle East as exotic entities viewed through a colonialist and imperialist perspective (Said, 1978). Even the way they are dressed proves they are "different" from Western women. Dressed in a form-fitting, revealing cheongsam, a traditional Chinese garment modified to fit the lens of the Western male gaze, Suzie Wong becomes the object of exotic desire, and Michelle Yeoh in Tomorrow Never Dies does not quite fit in at a gala with her high-collared dress when compared to the white guests (Wang, 2010).

Some roles may not be as obviously costumed as Michelle Yeoh, but still fall victim to same stereotypes that have plagued Asian women. In Ex Machina (2015), Sonoya Mizuno plays Kyoko, Nathan's silent Japanese servant who does not understand English. Not only is she mute, but she is also compliant and obedient, serving Nathan without complaint despite his mistreatment, even fulfilling his sexual desires. She has been programmed to fit the submissive "geisha girl" stereotype, and the image of a demure Asian woman serving a white man traps the viewer into accepting this is how it must be, as it does with Caleb when he first meets Kyoko. Because it is a stereotype that he has been exposed to before and has come to believe as true, he does not question whether or not Kyoko is human until she later reveals she is an android like Ava (Chang, 2015). When asked to comment on the use of Asian stereotypes in his film in an interview with Cinematic Essential, director Alex Garland said: 
Sometimes you do things unconsciously, unwittingly, or stupidly, I guess, and the only embedded point that I knew I was making in regards to race centered around the tropes of Kyoko [Sonoya Mizuno], a mute, very complicit Asian robot, or Asian-appearing robot, because of course, she, as a robot, isn't Asian. But, when Nathan treats the robot in the discriminatory way that he treats it, I think it should be ambivalent as to whether he actually behaves this way, or if it's a very good opportunity to make him seem unpleasant to Caleb for his own advantage. (Nash, 2015)

Although Garland attempts to excuse his use of stereotypes in the film through Nathan's programming Kyoko as an android without a race does not absolve her of the stereotypes attributed to her. According to author Sharon Chang, "Race isn't biological or written into human DNA. It's socio-politically constructed and assigned usually by those in power. Kyoko is Asian because she has been made that way not only by her oppressor, Nathan, but by Garland himself, the omniscient creator of all” (Chang, 2015). Garland's choice to have a Japanese actress to play Kyoko in an emotionless and subservient role reinforces racial and gender stereotypes that have proven to be harmful to Asian women outside of the realm of fiction and film. Kyoko continues to be mistreated throughout the film, but is given no agency or power due to her status as a silent, serving robot and sex object. When she collaborates with Ava to kill Nathan to escape him at the end of the film, she is destroyed by Nathan after she stabs him and Ava is left standing. Not once does Kyoko speak. 
Kyoko's role at the end of the film is reminiscent of the "good Asian" stereotype, where an Asian character makes a sacrifice to aid or save the white hero. In Ex Machina, Kyoko's demise is just one stepping stone for Ava, an android played by Alicia Vikander, to escape Nathan and his facility and find freedom. Furthermore, Nathan builds a Chinese robot and names her Jade; it is as if Garland could only come up with a stone commonly associated with China to name his character. A name might not be seen as doing the same harm as Kyoko's obvious docile obedience, but it is still rooted in the same historical typecasting of Asians. Like Kyoko, Jade is also another stepping stone for Ava. Although Ava could have taken the skin from any other android to fix her parts and make her appear fully human, she chooses to take the skin from Jade - subtly conveying that Asian bodies are only there to serve whites.

Stereotyping of Asian Men in Hollywood Film

Asian men also suffer from their own set of stereotypes. Charlie Chan, created by Earl Derr Briggs, was portrayed by three white men for 18 years from 1931-1949. By having only white actors portray an Asian man, Hollywood was again reinforcing the idea of Asia as a monolith, "lumping together diverse ethnic groups and portraying one-dimensional stereotypes that fed into and strengthened public perceptions of what Asians and Asian-Americans were like" (Mok, 1998, p. 191). Although Chan was intelligent and wise, spouting "fortune cookie" bouts of wisdom and outsmarting the police, these positive qualities were projected onto the white actor while his accent and eyes would be attributed to the Asian character. He would also embody the stereotype of 
the Asian man as effeminate and asexual (Mok, 1998). There are exceptions to this, however, such as Sessue Hayakawa in the 1910s and 1920s. Handsome, sophisticated, and a sex symbol of his times, he garnered popularity as an Asian movie idol. Despite his fame, however, he was still categorized as exotic and different, and he played villainous roles akin to the "dragon lady" stereotype (Mok, 1998). Bruce Lee, as well, would subvert the desexualization of Asian men with his roles showcasing his martial arts prowess and his tenacity. He showed America a different Asian-American face than what they were used to, fighting back against racial slurs and rising to popularity. However, Hollywood still wanted to box him in stereotypical roles and depicted him as exotic and foreign, so he turned to the Hong Kong film industry for more nuanced performances (Shimizu, 2012).

Furthermore, films of the late twentieth century and the present still turn to the same stereotypes that have plagued Asians for decades. In Rush Hour 2 (2001), Jackie Chan plays Lee, a respectful but ignorant Kung Fu master with no interest in sex. In John Hughes' iconic coming-of-age flick, Sixteen Candles (1984), Gedde Watanabe plays Long Duk Dong, a foreign exchange student from an undefined Asian country whose character is built on exaggerated stereotypes and racist humor. Although his role is meant to be comedic, the audience is not laughing with him, but at him and his seemingly backward, socially inept ways. He bumbles his way through American high school, a land completely foreign to him (just as he is presented as the outsider), spouting stilted English and using a spoon and fork like chopsticks. He first appears in the film hanging upside down from a top bunk bed, waggling his eyebrows at Molly Ringwald's Samantha 
as he says, "What's happenin', hot stuff?” Her response is a blank look, shooting him down without a word, while "a gong sounds off in the background" (Chow, 2015). This clanging of a gong seems to follow Long Duk Dong whenever he appears, linking him to the "oriental" sound effect characteristic of Asian stereotypes.

His other lines are not much better: After a high school dance, he jumps out from a tree as he cries out, "Oh, sexy girlfriend!" In another scene where he is found lying in the ground after a drunken night, he exclaims, “Oh, no more yanky my wanky. The Dongle needs food!" In addition, even if he does find a girlfriend, their relationship is built on reversed gender stereotypes that do not portray Long Duk Dong in a positive light. His girlfriend, "Lumberjack," towers over him, and when they hug, his head is on her chest instead of the other way around. "The gender roles are switched," Kent Ono and Vincent Pham write in their book, Asian-Americans And The Media. "While this representation aims to provide comic relief, it both feminizes Asian-American men and simultaneously constructs alternative gender and sexuality as aberrant” (Chow, 2015). Although Long Duk Dong surely got some laughs out of the audience, other viewers cringed at the racist caricature and Asian-Americans felt the repercussions of such a stereotypical portrayal. "Every single Asian dude who went to high school or junior high during the era of John Hughes movies was called 'Donger," says Martin Wong, who co-founded the magazine Giant Robot, which covers Asian and Asian-American pop culture. Eric Nakamura, the other founder of Giant Robot, adds, "It's like every bad stereotype possible, loaded into one character" (Macadam, 2008). It seems as if Asian men are also victim to extremes: In some portrayals, they are 
cold-hearted villains and ruthless Kung Fu masters, while in other films, are portrayed as "losers" who have all the brains but no social skills or clueless immigrants fresh off the boat.

The Effects of Stereotyping and Marginalization on the Industry

Still, it can be argued that stereotypes are derived from a sliver of truth, and should not be taken seriously. For example, when asked to comment if she believed she was perpetuating stereotypes of Asian-American women, actress Nancy Kwan of The World of Suzie Wong and Flower Drum Song "has stated that she was trying to enact roles to the best of her ability and that perhaps people are reading too much into these media images" (Mok, 1998, pp. 195-196). Furthermore, at University of Pennsylvania's Annenberg School for Communication, Ji Hoon Park, Nadine Gabbadon, and Ariel Chernin (2006) performed a study aiming to understand the implications of racial stereotypes in comedy by analyzing audience reactions to a showing of Rush Hour 2 (2001). Their results showed viewers agreed that because it was, for example, an Asian character making a joke about Asians, it was acceptable (compared to someone white making a joke about Asians). When interviewed, Asians were quick to point out stereotypes in the film, but did not take offense to Chan's or Zhang's roles as a desexualized martial arts artist and a seductive and dangerous villainess, respectively. It was also noted that seeing Asians in main roles in a film was already impressive in an industry where Asians are practically invisible (Park et al., 2006). 
However, harm lies in the dismissal of these stereotypes. When portrayed as humorous, stereotypes can normalize a misinterpretation of people of color, caging them in singular roles when the reality shows them to be well-rounded people with lives and stories of their own. Without critical discourse, stereotypes run the risk of perpetuating ignorance. By only portraying Asians in a certain way, the audience comes to see Asians as this stereotype if they are not exposed to any other more realistic role (Park et al., 2006). In addition, while Kwan is one example of an Asian actor who did not see the concern over criticism of Asian-American representation in media, critics and others in the field disagree. Hwang, writer of the play M. Butterfly, addresses the acceptance of stereotyping Asian women as submissive, sacrificing herself for a white man:

What would you say if a blonde homecoming queen fell in love with a short Japanese businessman? He treats her cruelly, then goes home for three years, during which time she prays to his picture and turns down marriage from a young Kennedy. Then, when she learns he has remarried, she kills herself. Now I believe you would consider this girl to be a deranged idiot, correct? But because it's an Oriental who kills herself for a Westerner-ah!you find it beautiful. (Hwang, 1986, p. 17)

Hwang points out the opposing situations to emphasize the unjust way Asian women are treated in media, or in the realm of this paper, film. By boxing Asians into stereotypical roles and disallowing them proper, well-rounded representation, Hollywood emphasizes Asians are not worthy of the same treatment or the same stories as whites. It is also 
difficult for Asian-American actors to be cast in a lead role, let alone one that is not typecast. Even films set in Asia often have a white actor as the lead. Tom Cruise plays the protagonist in The Last Samurai (2003) even though it is set in Japan, while Ken Watanabe, a renowned Japanese actor, was cast in a supporting role. He also played a supporting role in Godzilla (2014), another film set in Asia but with Asian actors as the supporting roles and whites as the leads. Jet Li and Jackie Chan, both widely famous in Asia and well-known internationally, still fell into the same trap when cast in The Forbidden Kingdom (2008), where their roles supported the white hero thrown into China (Chong, 2016).

Because of the history of marginalization of Asians in film and how it still persists despite the United States" "politically correct" culture and industry attempts to create more diverse roles, Asian-American actors still struggle to find roles that are not typecast or stereotyped. It is not difficult to find an Asian actor who has faced a typecasted audition at least once in his or her career, and according to author Nancy Yuen, "Asian-American actors have told me they are just seen for their race...Usually casting calls specify if they want character actors or leading men, but with Asian actors they see both types across ages, from 20 to 50. And if you're looking for a villain, any Asian will do" (Teng, 2016). Hollywood has created the idea of a homogenous Asian identity over time; Chinese actors will play Korean characters, and Korean actors will play Chinese characters. As long as the actor is Asian, then it must all be the same according to Hollywood. Casting directors also may base their "idea of what makes a good Asian actor derives from Hollywood's previous depictions of Asians" (Teng, 2016), which was the 
case with Garrett Wang, who played Harry Kim in Star Trek: Voyager (1995). When auditioning for the part of a member of the Japanese mafia, he imitated the accent of famous Japanese actor Toshiro Mifune. When told that was not the accent the casting director was looking, he switched to a stereotypical Cantonese accent made popular by Charlie Chan films. It was exactly what she wanted to hear, and he walked out (Teng, 2016).

Korean-American actress Arden Cho has also spoken about Asian-American representation in Hollywood, and how the industry should break away from stereotypical roles. In her career, she tries to avoid playing stereotypical roles like "sexy, hot Asian girl" or an "old, white guy's super young Asian wife." She also lamented the lack of roles given to Asian actors to begin with when she said, "Hollywood always takes shots on no-named actors, always if they're white. How many times have you guys seen a no-named white girl or white guy become famous overnight because they were the lead? They do not take a chance with an Asian actor" (Kim, 2017). Her proclamation is not entirely an exaggeration. According to an infographic from the USC Annenberg School for Communication and Journalism (2016), only one percent of lead roles in films go to Asians, and only one in twenty speaking roles go to Asians. She is only one of other Asian-American actors speaking up about lack of representation; several others have spoken up, as well. Lana Condor, a young Vietnamese-American actress who made her film debut in X-men: Apocalypse (2016), states:

It's very frustrating because I don't think that the roles aren't out there, they're just not written. Basically, if I audition for something, 
sometimes I feel like they're bringing me in to see if they can fill a diversity quota. Or I'm auditioning for an Asian-American girl struggling with adapting to a society that might not love her as much as someone who's white. I love portraying that because that's so prevalent in society, but at the same time, it would be really awesome to play girl next door—not just the Asian girl next door. It's not everything that defines us as actors. (LADYGUNN, 2016)

Korean-American John Cho (known for his role as Hikaru Sulu in the new Star Trek films) has also contributed to the discussion, lamenting the lack of representation in Hollywood and speaking out about what should be done about it. John, like Arden, has faced racism in his career and tries to avoid taking roles that perpetuate Asian stereotypes. When he was cast as the love interest in ABC's sitcom Selfie opposite Karen Gillan, he called it "revolutionary" (Haruch, 2014).

To refute the argument that movies with people of color in main roles do not sell as well, or that there are no Asian-American actors with the same popularity power to draw in audiences as white A-list stars, Hunt and Ramón (2015) of UCLA's Ralph J. Bunche Center for African American Studies conducted a study that showed movies with more diverse casts perform better at worldwide box offices. Their second annual Hollywood Diversity Report, conducted in 2015, found that 2013 films with $21-30 \%$ minority roles peaked at the median global box office, revealing a shift in market over time that pointed towards audience desire for more diversity in entertainment. The study also concluded "for 2012, median worldwide box office was actually highest for the 15 
films with casts that were from 31 percent to 40 percent minority ( $\$ 130.5$ million), the cast diversity interval that contains the minority share of the U.S. population" (Hunt and Ramón, 2015, p. 48).

Effects of Stereotyping and Marginalization on Asian-Americans in Society

When Asian women are only portrayed as submissive and docile by Hollywood, this feeds into the belief that Asian women are like this in reality; being perceived as exotic and submissive contributes to a higher risk of sexual assault, as if they are somehow “asking for it” (Rajgopal, 2010). Additionally, because Asian-Americans are fed idealized Western standards, they want to emulate them, and sometimes see white people as "better" because of negative stereotypes. In order to be accepted into America, Asians have to assimilate, and if their only source of portrayal in film are these stereotypes, then they can come to believe that this is how America accepts them to be and may internalize these stereotypes. Asians are also portrayed as perpetual foreigners, and the image of a bumbling, exaggerated FOB (Fresh Off The Boat) with little knowledge of English is a common one.

Some Asian-Americans find it difficult to pursue relationships, especially romantic ones, with other Asian-Americans due to preconceived notions about their race (Mok, 1998). They have commented on the contrasting stereotypes of Asian men and women, stating that the men were portrayed more negatively than women; Asian men are perceived as less socially skilled or seen as the enemy. In an interview with an Asian-American commenting on movies featuring Asians, Lee (1991) states, "We have 
all these Vietnam movies, and they are called 'gooks,' or 'Japs,' and they are usually men-like laundrymen or men with pigtails, so I think it is very hard to be an Asian male" (p. 132). Therefore, these stereotypes are not consumed blindly, but instead are associated with feelings of guilt and anger for feeding into stereotypes while wanting to break away from Western standards of beauty and society perpetuated by the media (Mok, 1998).

Asians are also plagued by the "model minority" stereotype, which parade them as an example for people, showing them to be intelligent, overachieving, and technologically savvy. The term first appeared in the 1960s during the Civil Rights movement, romanticizing the Asian diaspora as an exemplary ethnic minority "who fulfill the 'American Dream' by overcoming harsh circumstances and discrimination while remaining quiet and submissive" (Chao, Chiu, Chan, Mendoza-Denton, \& Kwok, 2013). Journalists purposely used this term to praise Asian-Americans for not engaging in civil protest or unrest, creating a divide between Asian-Americans and other people of color, especially African-Americans, that still exists today (Shankar, 2015). The term "model minority" may disguise itself as positive and well-meaning, but it is ultimately meant to maintain white supremacy and divides Asian-Americans from other people of color. Furthermore, in Zhang's (2010) study on how Asian-Americans were perceived in different areas, such as academic standing and likelihood to initiate friendship, it was found that Asians were in fact seen as being more successful with a tendency to excel more in life. This stereotype can undermine the struggles of Asians who do not fit this "model minority." The study also found Asians were more likely to also be perceived as 
antisocial, awkward, and lacking proper communication skills, which could lead to peer rejection (Zhang, 2010).

In addition, being seen as successful because of one's race or lauded as an example minority has detrimental societal implications, including one's academic life. In one instance, two top public schools in the Silicon Valley of Northern California saw an influx of Asian students and an exodus of white students and their parents, who avoided the schools because they were "too Asian" and had too many "excessively competitive and single-minded" Asian parents (Hwang, 2005). Asian-American college applicants also face quotas set by universities, hindering them from achieving the success they have worked so hard for and supposedly are supposed to be examples of (Shankar, 2015). Once they reach the workforce, Asian-Americans are also not exempt from racial discrimination or the "bamboo ceiling" despite aforementioned educational success or perception thereof. Christina Shu Jien Chong emphasizes how the model minority does more harm than good:

Society fails to realize that educational success does not automatically translate into equal pay or employment in industries dominated by Whites. For example, APAs [Asian Pacific American] are generally paid far less than Whites with the same educational levels. APAs receive a lower return on their educational investment (worse salaries), which forces them to seek higher education with 'great fervor.' In 2010, APAs were $4.8 \%$ of the U.S. population, but held only $2.1 \%$ of board of 
director seats in the Fortune 500 companies. Whites held $90 \%$ of the director seats when they only made up $72 \%$ of the U.S. population. (Chong, 2016)

Another study done by Melody Chao, Chi-yue Chiu, Wayne Chan, Rodolfo

Mendoza-Denton, and Carolyn Kwok demonstrates that the "model minority" stereotype is a shared reality shared among Americans, especially European-Americans. The United States has come to expect Asian-Americans to play into the successful yet submissive "model minority" role.

Not only does this stereotype create a skewed and distorted image of Asian-Americans, but it also homogenizes distinct ethnic groups within the Asian continent that consist of diverse cultures and over hundreds of languages (Chao, et al., 2013; Kawai, 2005). Like some portrayals of Asians in Hollywood films, the "model minority" stereotype merges distinct ethnocultural backgrounds into a monolith or creates the idea that these cultures are interchangeable.

\section{Conclusion}

The marginalization and stereotyping of Asian-Americans in Hollywood has shaped the perception of Asian-Americans not only in pop culture and the entertainment industry, but also in society. Stereotypes that were born out of fear or the desire to separate Asian-Americans from white people or other people of color have been emphasized by portrayals in the media, leading to consequences felt by Asian-Americans. By perpetuating a singular identity or core characteristics of what Asians should be, such as a "model minority" or portraying Asian women as submissive and docile, Hollywood 
continues to deprive Asians of well-rounded, dimensional characters that are more than a stereotype. While there are some Asians who do embody characteristics often seen in the media, such as soft-spoken or intelligent with inclinations towards math and science (which originated because of language barriers in the immigrant community), it is dangerous to accept this as the only Asian identity; the Asian-American population today is much more diverse.

However, as discouraging as these stereotypes and the lack of representation of Asian-Americans in film may be, people are moving forward. Although current films still continue to bypass Asian actors in favor of white ones, Asian-American actors in the industry are speaking up about the unfairness. Hollywood, too, is slowly doing its part to cast ethnically correct actors for Asian roles_-Disney's upcoming live action adaptation of Mulan has cast Chinese actress Liu Yifei as the titular protagonist. Other films are also beginning to break down boundaries, casting Asians in roles that they would not have been in fifty years ago. Hailee Steinfeld, who is part Filipino, stars in The Edge Of Seventeen (2016), a coming-of-age comedy drama film. Hayden Szeto stars opposite her as her love interest, Erwin Kim. Instead of being portrayed as a socially awkward, quiet loner, Erwin is given a more well-rounded role, and his character feels like a high schooler that just happens to be Asian.

These nuanced performances are key to increasing diversity within film. While this does not excuse Hollywood's blatant racism by continuing to cast white actors in yellowface or "whitewash" Asian roles, by consuming media critically and continuing to 
speak up against the marginalization of Asians in Hollywood, the entertainment industry continues to make steps forward in the right direction. 


\section{References}

Chao, M. M., Chiu, C., Chan, W., Mendoza-Denton, R., \& Kwok, C. (2013). The model minority as a shared reality and its implication for interracial perceptions. Asian American Journal Of Psychology, 4(2), 84-92. doi:10.1037/a0028769

Chang, S. (2015, May 30). How 'Ex Machina' Abuses Women of Color \& Nobody Cares Cause It's Smart [Blog post]. Retrieved from http://multiasianfamilies.blogspot.com/2015/05/how-ex-machina-abusesWomen-of-color.html

Chow, K. (2015, February 6). What's So 'Cringeworthy' About Long Duk Dong in 'Sixteen Candles'? NPR. Retrieved from https://www.npr.org/sections/codeswitch /2015/02/06/384307677/whats-so-cringe-worthy-about-long-duk-dong-in-sixteencandles

Christina Shu Jien, C. (2016). Where Are the Asians in Hollywood? Can §1981, TITLE VII, Colorblind Pitches, and Understanding Biases Break the Bamboo Ceiling?. Asian Pacific American Law Journal, 21(1), 29-79.

Haruch, S. (2014, September 28). In 'Selfie,' John Cho Gets An Unlikely Shot As A Romantic Lead. NPR. Retrieved from https://newrepublic.com/article/131631/still-okay-make-fun-asians

Hodges, G. R. (2012). Anna May Wong: From Laundryman's Daughter to Hollywood Legend. Hong Kong: Hong Kong University Press.

Hunt, D., \& Ramón, A. (2015). 2015 Hollywood Diversity Report: Flipping the Script (Rep.). Ralph J. Bunche Center for African American Studies at UCLA. 
Hwang, D. H. (1986). M. Butterfly. New York: Penguin Books.

Hwang, S. (2005, November 19). The new White flight. The Wall Street Journal.

Retrieved July 30, 2006, from http://wsjclassroom.com/teen/

teencenter/05nov_whiteflight.htm

Kawai, Y. (2005). Stereotyping Asian-Americans: The Dialectic of the Model Minority and the Yellow Peril. Howard Journal Of Communications, 16(2), 109-130.

doi:10.1080/10646170590948974

LADYGUNN. (2016, August 15). Lana Condor [Blog post]. Retrieved from http://ladygunn.com/people/lana-condor/

Lee, C. A. (1991). On being Asian-American. In J. F.J. Lee (Ed.), Asian-Americans (p. 132). New York: New Press.

Macadam, A. (2008, March 24). Long Duk Dong: Last of the Hollywood Stereotypes? NPR. Retrieved from http://www.npr.org/sections/codeswitch/2015/02/06/ 384307677/whats-so-cringe-worthy-about-long-duk-dong-in-sixteen-candles

Micheline, J. (2015, May 21). Ex Machina: A (white) Feminist Parable for Our Time [Blog post]. Retrieved from http://womenwriteaboutcomics.com/2015/05/21/ex-machina-a-white-feminist-par able-for-our-time/

Mok, T. A. (1998). Getting the message: Media images and stereotypes and their effect on Asian-Americans. Cultural Diversity And Mental Health, 4(3), 185-202. doi:10.1037/1099-9809.4.3.185 
Nash, C. (Interviewer) \& Garland, A. (Interviewee). (2015). Interview with Alex Garland, Writer/Director of Ex Machina [Interview transcript]. Retrieved from Cinematic Essential Web site:

http://www.cinematicessential.com/interview-with-alex-garland-writerdirectorof-ex-machina/

Park, J., Gabbadon, N. G., \& Chernin, A. R. (2006). Naturalizing Racial Differences Through Comedy: Asian, Black, and white Views on Racial Stereotypes in Rush Hour 2. Journal Of Communication, 56(1), 157-177. doi:10.1111/j.14602466.2006.00008.x

Rajgopal, S. S. (2010). 'The Daughter of Fu Manchu': The Pedagogy of Deconstructing the Representation of Asian Women in Film and Fiction. Meridians: Feminism, Race, Transnationalism, 10(2), 141-162. doi:10.2979/meridians.2010.10.2.141

Rose, A. (2016, July 20). whitewashed Out: "Ghost in the Shell” and Hollywood's Problem with whitewashing Asian Characters [Blog post]. Retrieved from http://now.org/blog/whitewashed-out-ghost-in-the-shell-and-hollywoods-problem -with-whitewashing-asian-characters/

Said, E. W. (1978). Orientalism. New York: Pantheon Books

Shankar, S. (2015, April 06). Fifty years on, the overachiever stereotype is still hurting Asian Americans. Quartz Media LLC. Retrieved from https://qz.com/376677/ Watch-new-documentary-proves-model-minority-stereotype-hurts-more-thanit-helps/

Shimizu, C. P. (2012). Straitjacket Sexualities : Unbinding Asian-American Manhoods in 
the Movies. Stanford, CA: Stanford University Press.

Smith, S., Choueiti, M., Pieper, K., Gillig, T., Lee, C., \& DeLuca, D. (2015). Inequality in 700 Popular Films: Examining Portrayals of Gender, Race, \& LGBT Status from 2007 to 2014. The Harnisch Foundation.

Teng, E. (2016, March 16). Why Is It Still Okay to Make Fun of Asians? New Republic. Retrieved from https://newrepublic.com/article/131631/still-okay-make-fun-asians

Thakore, B. K. (2014). Must-See TV: South Asian Characterizations in American Popular Media. Sociology Compass, 8(2), 149-156. doi:10.1111/soc4.12125

Wang, H. (2013). Portrayals of Chinese Women's Images in Hollywood Mainstream Films--An Analysis of Four Representative Films of Different Periods. China Media Research, 9(1), 75-79.

Zhang, Q. (2010). Asian-Americans Beyond the Model Minority Stereotype: The Nerdy and the Left Out. Journal Of International \& Intercultural Communication, 3(1), 20-37. doi:10.1080/17513050903428109 